the cell type studied.

Although RU486 is usually viewed as a glucocorticoid and progestin antagonist, it is of note that it possesses some degree of agonist activity in some assay systems ${ }^{8}$, suggesting, as well, that risks may be associated with the use of RU486 in HIV infection. Before this drug is used as an abortifacient in HIV-infected women, or as a potential antagonist of Vpr-mediated cell dysregulation, any stimulatory effects on HIV-1 replication should be assessed in a wide variety of cell types including those of primary origin.

H. SOUDEYNS, M.A. WAINBERG

McGill University AIDS Centre, Jewish General

Hospital, Montréal, Québec, Canada, H3T $1 E 2$

H.S. present address:

Laboratoire d'immunopathologie

du SIDA département de médecine interne CHUV, 1011 Lausanne, Switzerland
1. Ayyavoo, V. et al. HIV-1 Vpr suppresses immune activation and apoptosis through regulation of nuclear factor kB. Nature Med. 3, 1117-1123 (1997).

2. Markham, P.D., Salahuddin, S.Z, Veren, K. Orndorff, S. \& Gallo, R.C. Hydrocortisone and some other hormones enhance the expression of HTLV-III. Int. . Cancer 37, 67-72 (1986).

3. Soudeyns, H., Geleziunas, R., Shyamala, G., Hiscott, J. \& Wainberg, M.A. Identification of a novel glucocorticoid response element within the genome of the human immunodeficiency virus type 1 . Virology 194, 758-768 (1993).

4. Ghosh, D. Glucocorticoid receptor-binding site in the human immunodeficiency virus long terminal repeat. J. Virol. 66, 586-590 (1992).

5. Kolesnitchenko, V. \& Snart, R.S. Regulatory elements in the human immunodeficiency virus type 1 long terminal repeat (LTR) responsive to steroid hormone stimulation. AIDS Res. Hum. Retroviruses 8 , 1977-1980 (1992).

6. Shafer, R.W. et al. Possible risk of steroid administration in patients at risk for AIDS. Lancet 1 934-935 (1985).

7. Glasgow, B.I., Steinsapir, K.D., Anders, K. \& Layfield, L.). Adrenal pathology in the acquired immune deficiency syndrome. Am. \%. Clin. Path. 84, 594-597 (1985).

8. Meyer, M.E. et al. Agonistic and antagonistic activities of RU486 on the functions of the human progesterone receptor. EMBO /. 9, 3923-3932 (1990).

\title{
Black market drugs are only the tip of the iceberg
}

To the editor-Your recent report ${ }^{1}$ on the poor availability of anti-viral drugs for India's more than three million HIV-positive, mentioned the use of black market drugs. Although the lack of legally acquired drugs is of course a major concern, it is just one of many obstacles standing in the way of effective anti-HIV treatment in India and other developing countries. Sadly, the use of black market drugs that have passed their expiration date is an established practise in many countries with no system to monitor drug quality and drug reactions ${ }^{2}$ as in, for example, the 1995 case of the theft and black market resale of ten-thousand doses of expired and potentially toxic tetanus and diphtheria vaccines in Burma $^{3}$. It is understandable that desperate patients turn to the black market as their only source of life saving drugs, however it is a dangerous practise both for the individual and the community.

Potentially, the use of anti-HIV multi drug cocktails that include poor quality drugs with exorbitant black-market price tags, could lead to the unecessary development of drug resistance. Anti-HIV multi-drug therapy requires careful and constant supervision over prolonged periods and suboptimal drug cocktails with only sporadic availability will have the effect of selecting and amplifying multidrug-resistant strains.
Apart from the fiscal constraints that limit the ability of most developing countries to buy adequate supplies of anti-HIVdrugs, few trained personnel to manage the demanding drug regimes and inadequate laboratory facilities to monitor CD4 cell and viral levels, are also major limitations to effective antiHIV therapy.

Currently there is no effective treatment available to the vast majority of India's HIV-positive patients. If anti-HIV drugs are to have any impact on India's growing populaton of HIV-positive patients, simplified laboratory tests that allow physicians to monitor patients' responses to the drugs ${ }^{4}$, are essential. Without them, it is likely that anti-HIV drugs, black market or otherwise, will have little effect.

\section{S.C. ARYA}

Centre for Logistical Research and Innovation M-122, Greater Kailash-II

New Delhi 110048, India

1. Jayaraman, K.S. AIDS patients demand drugs as government hesitates. Nature Med. 3, 943 (1997).

2. Sesay, M.M. Expiry date on pharmaceuticals - some worrying realities in Sierra Leone. Int. Pharmacy J. 8, 202-206 (1994).

3. Masood, E. Warnings raised over black-market vac cines. Nature 374, 669 (1995).

4. Zwerner, R.K. et al. A whole blod alternative to traditional methods for CD4 T-lymphocyte determination. f. Acqu. Imm. Def. Hum. Repro. 14, 31-34 (1997).

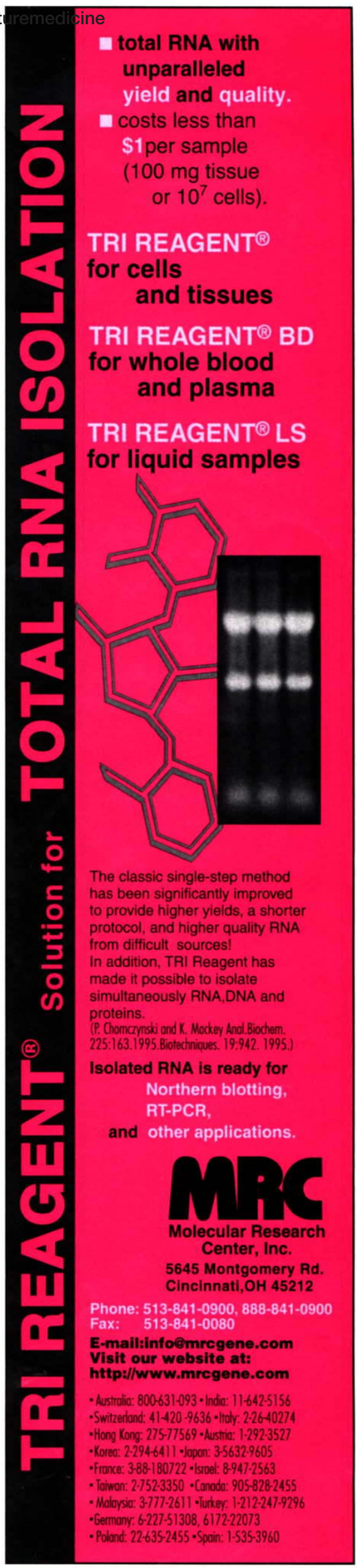

Circle No. 63 on Reader Service Card 